\title{
Relationships between vaccinations, herd introductions, and livestock losses in Northern Tanzania
}

Haseeb Ahmed ${ }^{1 \star}$ (D), Jonathan Yoder ${ }^{2}$, William de Glanville ${ }^{3}$, Alicia Davis ${ }^{4}$, Tito J. Kibona ${ }^{5}$ and Sarah Cleaveland ${ }^{3}$

${ }^{1}$ Department of Clinical Sciences, Sveriges Lantbruksuniversitet, Uppsala, Sweden, ${ }^{2}$ School of Economic Sciences, Washington State University, Pullman, WA, USA, ${ }^{3}$ Institute of Biodiversity, Animal Health and Comparative Medicine, College of Medical, Veterinary and Life Sciences, University of Glasgow, Glasgow, UK, ${ }^{4}$ School of Social and Political Science, University of Glasgow, Glasgow, UK and ${ }^{5}$ Nelson Mandela African Institute of Science and Technology, Arusha, United Republic of Tanzania

${ }^{*}$ Corresponding author. Email: haseeb.ahmed@slu.se

(Received 7 October 2020; revised 8 June 2021; accepted 8 June 2021; first published online 9 August 2021)

\begin{abstract}
This article examines the relationships between livestock vaccinations, herd introduction decisions, and livestock disease-related outcomes. We develop a theoretical model and derive testable hypotheses about the relationships between these outcomes and practices and test them using two-stage least squares regression analysis. We find that vaccinations reduce disease-related livestock deaths, implying that vaccine availability and use may improve herd and household welfare. We do not find robust evidence of increase in disease-related illness due to herd introductions. Our results highlight the role of livestock vaccinations in safeguarding herd value, which is connected to broader household welfare for livestock keepers of Eastern Africa.
\end{abstract}

Keywords: household production; infectious disease; livestock vaccinations; Tanzania

\section{Introduction}

Livestock health is economically important for livestock keepers of East Africa who rely on their livestock for income, wealth, and nutrition. However, livestock health and productivity in the region are constrained by multiple factors, including infectious disease. Livestock disease and health outcomes depend on a host of environmental factors and household herd management decisions. Management strategies like livestock quarantine and vaccination can limit individual animal exposure and susceptibility and are valuable measures to prevent diseases that negatively affect households. However, factors associated with adoption of these measures and their costs and benefits are not well quantified in low- and middle-income countries (Knight-Jones, McLaws, and

(c) The Author(s), 2021. Published by Cambridge University Press on behalf of the Northeastern Agricultural and Resource Economics Association. This is an Open Access article, distributed under the terms of the Creative Commons Attribution licence (http://creativecommons.org/licenses/by/4.0/), which permits unrestricted re-use, distribution, and reproduction in any medium, provided the original work is properly cited. 
Rushton 2017; Railey et al. 2018; Limon et al. 2020). Furthermore, the uptake of livestock vaccines is hampered in Tanzania and East Africa more broadly by several factors, including limited supply of quality vaccines, poor vaccine transport infrastructure, credit constraints, and information asymmetries (Homewood et al. 2006; Railey et al. 2018; Railey and Marsh 2019; Waithanji, Kairu-Wanyoike, and Liani 2019; Waithanji, Mtimet, and Muindi 2019).

When livestock losses do occur, replacing livestock (restocking by introducing new animals into the herd) after a death or an abortion through purchase, lending, or by gift receipts within informal social networks is a common and important household strategy for herd maintenance (McPeak and Barrett 2001; McPeak 2006; Toth 2015). However, livestock introductions from outside the herd can also be a source of infectious disease (Fèvre et al. 2001; Gardner, Willeberg, and Mousing 2002; Marshall, Carpenter, and Thunes 2009). Risks of pathogen transmission and consequent losses due to restocking may be more acute in pastoral areas, where herds are grazed communally and access to veterinary services is limited (Selby et al. 2013).

This article examines the relationships between vaccination decisions for illness prevention, animal introduction decisions for herd maintenance, and disease-related livestock losses in the form of livestock death and abortions. We examine these relationships using primary survey-based cross-sectional data collected in northern Tanzania. To do so, we develop a theoretical model of livestock management decisions in the context of herd disease challenge and derive a set of testable hypotheses relating to the above objective. Because livestock health management practices are theoretically responsive to disease and illness risk through herd owner disease management incentives, management activities and disease outcomes are jointly determined. Therefore, we use instrumental variable regressions to test the hypotheses about livestock introductions and vaccinations and their relationship with livestock abortions and disease-related deaths.

We find evidence that vaccinations are effective in reducing disease death rates, especially in small stock (i.e., sheep and goats), suggesting that vaccination availability and use may improve herd and household welfare. However, no sampled household vaccinated against more than three livestock diseases, possibly due to credit constraints and a lack of vaccine availability or access to veterinary services (Homewood et al. 2006; Railey et al. 2018; Waithanji, Mtimet, and Muindi 2019). We do not find robust evidence of herd introductions as a risk factor for increase in disease-related deaths and abortions in our sample.

This article contributes to the literature related to livestock vaccinations in East Africa (Marsh et al. 2016; Railey et al. 2018, 2019; Waithanji, Mtimet, and Muindi 2019) by examining households' vaccination adoption decisions and estimating the benefits of livestock vaccination, especially in terms of reducing livestock mortality rates. While livestock acquisition and herd dynamics are extensively studied in relation to poverty, poverty traps, and consumption smoothing (Fafchamps, Udry, and Czukas 1998; Lybbert et al. 2004; Barrett 2005; Carter and Barrett 2006; Kazianga and Udry 2006; Santos and Barrett 2017), the literature on demand for vaccinations, herd introductions, and its relationship with animal health outcomes is scant. Our results have important policy implications in terms of reaching the goal of healthier livestock, which is critical in multidimensional poverty alleviation through various channels like wealth, income, health, and nutrition in livestock-dependent households. 


\section{A model of vaccination use and livestock introductions}

A theoretical model of the relationship between livestock introductions, disease outcomes, and vaccinations is developed next as a foundation for deriving hypotheses and to guide estimation. Herd replacement and dynamics and disease management decisions under drought and disease risk have been modeled separately in the literature (Fafchamps, Udry, and Czukas 1998; Marsh et al. 2016; Ahmed et al. 2018). Our theoretical model extends this literature by providing an integrated framework of disease management and herd maintenance decisions under disease risk.

We assume that households act as if to maximize net herd returns by utilizing quasi-fixed inputs such as available labor and accessible land, livestock vaccination investments, and herd introductions, where herd introductions can be both a response to disease losses and a source of disease introductions into the herd. Although not a focus of this article, we also account for drought losses because they can be substantial in these environments, and we capture them in our data.

For the theoretical model, we assume one livestock type and combine disease-related deaths and/or abortions into a general concept of livestock loss, but we later separate these for estimation. To support our analysis based on crosssectional data in a parsimonious framework, we develop a static, partial agricultural household model (assuming separability between consumption and production decisions (as in Carter 1988, Taylor and Adelman 2003, Ahmed et al. 2018) that focuses on how the potential for livestock disease or drought loss provides an incentive to both vaccinate to reduce loss and introduce animals for loss replacement and/or for portfolio management. The household's net returns from livestock are characterized as follows:

$$
\max _{l, v, n} \pi=p(y(l ; k)+n)(1-\delta(v, n ; g, \rho, \gamma))-m n-c v-w l-r
$$

where $p$ is the marginal value of an animal to the household in terms of its productivity in the herd, $y$ is the "initial" herd size prior to introductions and losses, which might be thought of as a target or preferred herd size in the absence of livestock losses. Labor available for husbandry, $l$, and carrying capacity, $k$, are quasi-fixed with respect to herd size decisions, and therefore, $y$ is quasi-fixed in the model.

The loss rate, $\delta(\cdot) \in[0,1]$, is the fraction of animal units lost by drought and disease through abortions and/or death. Vaccinations, $v$, reduce losses at a decreasing rate $\left(\delta_{v}<\right.$ $0, \delta_{v v}>0$ ), reflecting the standard assumption of diminishing marginal benefit of input use. Introductions to the herd via purchase or gifts, denoted by $n$, are assumed to increase mortality at an increasing rate $\left(\delta_{n}>0, \delta_{n n}>0\right)$, reflecting compounding disease contagion with increased new contacts (e.g., Anderson and May 1992). Furthermore, the marginal value of vaccinations increases with an increase in introductions $\left(\delta_{\mathrm{v} n}=\right.$ $\left.\delta_{n \mathrm{v}}>0\right)$, where subscripts indicate partial derivatives. These interaction effects reflect the increase in the marginal benefit of vaccines in terms of disease control when the potential risk of disease transmission increases. The loss rate is also assumed to be positively associated with a background disease burden, $\rho,\left(\delta_{\rho}>0\right)$; general grazing/feeding practices, $g,\left(\delta_{\mathrm{g}}>0\right)$ that we take as quasi-fixed and related to land tenure and cultural norms such as communal or zero grazing (as in Ahmed et al. 2018); and rainfall, $\gamma$, which we assume reduces losses, i.e., $\delta_{\gamma}<0$ (based on the evidence that droughts adversely affect livestock health and mortality [Fafchamps, Udry, and Czukas 1998; Ahmed et al. 2019]). General livestock grazing practices, $g$, and introductions, $n$, capture 
interherd contact, which is related to disease prevalence in the region (Bronsvoort et al. 2004; Rufael et al. 2008; Schoonman and Swai 2010; Ahmed et al. 2018).

The marginal cost of an introduction is $m$ (e.g., the market price of an animal), $c$ is the marginal cost of vaccination, $w$ is the cost of labor, and $r$ represents any purely fixed costs such as land or capital rent applicable to the livestock enterprise.

The first-order necessary conditions for maximizing with respect to the choice variables $v, n$, and $l$ are as follows:

$$
\begin{gathered}
\frac{\partial \pi}{\partial v}=-p \delta_{v}(y+n)=c \\
\frac{\partial \pi}{\partial n}=p(1-\delta)-p \delta_{n}(y+n)=m \\
\frac{\partial \pi}{\partial l}=p y_{l}(1-\delta)=w .
\end{gathered}
$$

Equation 2 implies that households choose to vaccinate to the point that the marginal benefit of vaccinations in terms of loss mitigation, $-p \delta_{v}(y+n)$, equals the marginal cost of vaccinations, $c$. Equation 3 implies that households will supplement after-loss herd size with introductions as long as the purchase cost is no greater than the in-herd value net of disease losses to introductions $(p(1-\delta))$ plus the marginal cost of disease transmission due to herd introduction, $-p \delta_{n}(y+n)$. Equation 4 implies that households choose to allocate labor for livestock management to the point that the marginal revenue product, $p y_{l}(1-\delta)$, is equal to the marginal cost of labor, $w{ }^{1}$

Given exogenous factors $\boldsymbol{\theta}=(p, m, c, w, g, \rho, k, \gamma)$, the first-order conditions (equations 2 and 3 ) implicitly define the optimal demand functions for vaccinations, $v^{*}=v(\boldsymbol{\theta})$, and introductions, $n^{\star}=n(\boldsymbol{\theta})$, which, in turn, imply an endogenous damage rate $\delta^{*}=\delta\left(v^{*}, n^{*} ; g, \rho, \gamma\right) \equiv \delta(\boldsymbol{\theta})$. Background disease risk $\rho$, weather $\gamma$, and general grazing practices $g$ have both direct effects on loss rates and indirect effects through vaccination and reintroduction demands. One might expect, for example, that a higher background disease risk $\rho$ would instigate more vaccination through its effect on the value of the marginal product of vaccination, which would partially offset the disease losses due to background disease risk. To the extent that communal grazing heightens herd interactions and disease transmission, herd loss and subsequent animal acquisition for replacement may lead to an additional (indirect) herd infection risk.

Livestock loss from illness is $L^{\star}=\delta^{\star}\left(y^{\star}+n^{\star}\right)$ and depends on endogenous introductions and vaccination use. The value of disease losses would be $p L^{\star}=p \delta^{\star}\left(y^{\star}+n^{\star}\right)$. Equation 4 implicitly defines the optimal demand function for labor, $l^{\star}=l(\boldsymbol{\theta})$.

Our hypotheses and implications for empirical strategies follow. Vaccinations reduce disease losses by $\left(\partial L^{*} / \partial v^{*}\right)=p \delta_{\mathrm{v}}\left(y^{*}+n^{*}\right)<0$, and this value is larger when the value of the herd is large, suggesting the following hypotheses:

\section{Hypothesis 1: Disease losses are negatively related to vaccinations.}

\footnotetext{
${ }^{1}$ Second-order sufficient conditions for a maximum are presented in the Supplementary Appendix.
} 
Hypothesis 2: Vaccination use is positively related to the value of the herd.

The marginal effect of herd introductions $n^{\star}$ on losses $L^{*}$ evaluated at $v^{*}, l^{*}$, and $n^{*}$ is represented by $\left(\partial L^{*} / \partial n^{*}\right)=\delta_{n}\left(y^{*}+n^{*}\right)+\delta^{*}>0$, suggesting

Hypothesis 3: Increase in herd introductions is positively associated with increase in disease losses.

While the hypotheses derived from the model are intuitive, this model highlights two issues that are important for guiding empirical methodology. First, $v^{\star}=v(\boldsymbol{\theta})$ and introductions $n^{\star}=n(\boldsymbol{\theta})$ are endogenous choices, driven by exogenous biophysical and economic factors. Disease losses $L^{*}=L\left(v^{*}, n^{*}, l^{*} ; g, \rho, k, \gamma\right)$ are directly affected by management decisions and a set of exogenous household characteristics and disease conditions and indirectly affected by management decisions by a broader set of exogenous variables. Second, the hypotheses each reflect model-based correlations between two endogenous variables conditional on exogenous factors. Thus, while we utilize regression methods to control for exogenous factors in assessing relationships, our regression results relating directly to hypotheses 1 through 3 should not be interpreted as implying direct causality in any given direction.

The endogeneity of vaccinations and introductions as factors affecting disease losses has important implications for formulating an econometric estimation strategy, but because the specifics of the available data also inform the estimation strategy, a description of the data is, therefore, provided next.

\section{Data}

Data were collected as part of the "Social, Economic and Environmental Drivers of Zoonotic Disease in Tanzania" (SEEDZ) project (Ahmed et al. 2019; de Glanville et al. 2020). A cross-sectional survey was conducted across six districts in Arusha Region (Arusha, Karatu, Longido, Meru, Monduli, and Ngorongoro Districts) and four districts in Manyara Region (Babati Rural, Babati Urban, Mbulu, and Simanjiro Districts) between January and December 2016. A multistage sampling design was used. Villages were selected from a spatially referenced list of all villages in the study area (from the Tanzanian National Bureau of Statistics [NBS]) using a generalized random tessellation stratified sampling approach (Stevens and Olsen 2004). Within each village, two to three subvillages were randomly selected, and data collection was performed at a central point within each village (up to 10 households were included in each subvillage based on the willingness to participate). In total, data were collected from 404 households in 49 subvillages, and the dataset was made up of one record (observation) per household collected from a questionnaire survey conducted with the household head. Some observations were dropped in our analysis due to missing data from an incomplete survey response, so the analysis was based on 386 observations.

Table 1 describes the variables used in the analysis, and Table 2 provides summary statistics. Vaccinations ( $v$ in our theoretical model) are the count of vaccine types used for different diseases within a household (variable names are presented in italics throughout). The diseases covered by these vaccinations include anthrax, foot-and-mouth disease, lumpy skin disease, black quarter, East Coast fever (ECF), contagious bovine pleuro-pneumonia (CBPP), peste des petits ruminants, and Rift Valley 
Table 1. Data description

\begin{tabular}{|c|c|}
\hline Variable & Definition \\
\hline Vaccinations & Count of different vaccinations applied to the herd in the past 12 months. \\
\hline [Stock] disease deaths & $\begin{array}{l}\text { Number of [Stock: cattle, sheep, or goats] reported dead due to disease in } \\
\text { the past } 12 \text { months. }\end{array}$ \\
\hline [Stock] abortions & $\begin{array}{l}\text { Number of [Stock: cattle, sheep, or goats] reported abortions in the past } \\
12 \text { months. }\end{array}$ \\
\hline Cattle introductions & $\begin{array}{l}\text { Number of cattle introduced into a household through market or } \\
\text { nonmarket transactions in the past } 12 \text { months. }\end{array}$ \\
\hline Sheep introductions & $\begin{array}{l}\text { Number of sheep introduced into a household through market or } \\
\text { nonmarket transactions in the past } 12 \text { months. }\end{array}$ \\
\hline Goat introductions & $\begin{array}{l}\text { Number of goats introduced into a household through market or } \\
\text { nonmarket transactions in the past } 12 \text { months. }\end{array}$ \\
\hline Cattle & Number of cattle present in the household net of introductions. \\
\hline Sheep & Number of sheep present in the household net of introductions. \\
\hline Goats & Number of goats present in the household net of introductions. \\
\hline Transhumance distance & $\begin{array}{l}\text { Euclidean distance between household's home and seasonal grazing } \\
\text { camp. Measured in kilometers. }\end{array}$ \\
\hline Grazing time & $\begin{array}{l}\text { Time taken by livestock keepers and animals to walk to grazing points, } \\
\text { measured in minutes. }\end{array}$ \\
\hline Watering time & $\begin{array}{l}\text { Time taken by livestock keepers and animals to walk to water points, } \\
\text { measured in minutes. }\end{array}$ \\
\hline Subvillage vaccinations & $\begin{array}{l}\text { Sub-village-level leave-out mean of vaccinations, which is calculated as } \\
\bar{v}_{i}=\left(\left(\sum_{j \neq i} v_{j}\right) /(N-1)\right) \text {, where } v_{i} \text { is the vaccination number of each } \\
\text { household and } N \text { is the number of households in the subvillage. }\end{array}$ \\
\hline Subvillage disease death & $\begin{array}{l}\text { Sub-village-level leave-out mean of the total livestock disease mortality, } \\
\text { which is calculated as } \bar{m}_{i}=\left(\left(\sum_{j \neq i} m_{j}\right) /(N-1)\right) \text {, where } m_{i} \text { is the } \\
\text { mortality number of household } i \text { and } N \text { is the number of households in } \\
\text { the subvillage. }\end{array}$ \\
\hline Subvillage abortions & $\begin{array}{l}\text { Sub-village-level leave-out mean of livestock abortions, which is calculated } \\
\text { as } \bar{q}_{i}=\left(\left(\sum_{j \neq i} q_{j}\right) /(N-1)\right) \text {, where } q_{i} \text { is the livestock abortion number } \\
\text { of household } i \text { and } N \text { is the number of households in the subvillage. }\end{array}$ \\
\hline Goat drought death & Number of goats died during the last drought. \\
\hline Sheep drought death & Number of sheep died during the last drought. \\
\hline Cattle drought death & Number of cattle died during the last drought. \\
\hline
\end{tabular}

fever. ${ }^{2}$ Vaccinations range from zero to three in our data, which implies that although vaccinations are being used, they do not cover the wide range of livestock diseases faced

\footnotetext{
${ }^{2}$ No Rift Valley fever vaccine was licensed in Tanzania at the time of the study. However, the vaccine may have been acquired across the border from Kenya. There can be potential recall bias in vaccination reporting, as households may not know for which diseases have animals been vaccinated against or may not remember such details.
} 
Table 2. Summary statistics $(N=386)$

\begin{tabular}{|c|c|c|c|c|}
\hline & Mean & Std. Dev. & Minimum & Maximum \\
\hline Vaccinations & 0.218 & 0.483 & 0 & 3 \\
\hline Cattle disease death & 1.50 & 6.30 & 0 & 100 \\
\hline Sheep disease death & 4.26 & 15.03 & 0 & 180 \\
\hline Goat disease death & 5.38 & 17.49 & 0 & 200 \\
\hline Cattle abortions & 0.59 & 2.70 & 0 & 40 \\
\hline Sheep abortions & 1.12 & 4.25 & 0 & 78 \\
\hline Goat abortions & 2.10 & 5.83 & 0 & 50 \\
\hline Cattle introductions & 1.61 & 7.25 & 0 & 94 \\
\hline Sheep introductions & 0.78 & 4.059 & 0 & 60 \\
\hline Goats introductions & 1.50 & 6.70 & 0 & 85 \\
\hline Cattle & 53.57 & 122.7 & 0 & 1,200 \\
\hline Goats & 61.19 & 120.11 & 1 & 1,000 \\
\hline Sheep & 63.85 & 174.7 & 1 & 1,800 \\
\hline Transhumance distance (km) & 10.34 & 25.36 & 0 & 281.58 \\
\hline Watering time (min) & 3.36 & 1.19 & 0 & 6.39 \\
\hline Grazing Time (min) & 69.7 & 123.22 & 0 & 1,440 \\
\hline Subvillage vaccinations & 0.215 & 0.254 & 0 & 1.33 \\
\hline Subvillage abortions & 0.80 & 2.18 & 0 & 20 \\
\hline Subvillage disease death & 1.59 & 2.89 & 0 & 17.85 \\
\hline Goat drought death & 2.61 & 14.15 & 0 & 200 \\
\hline Sheep drought death & 2.38 & 16.21 & 0 & 260 \\
\hline Cattle drought death & 2.78 & 15.2 & 0 & 200 \\
\hline
\end{tabular}

by households. Of the households in our sample, 81.5 percent reported having not vaccinated their livestock in the last 12 months, 16 percent reported using one type of vaccine, 2.5 percent reported using 2, and 1 percent reported using three. The most frequently used vaccines were for CBPP and anthrax, followed by vaccines for lumpy skin disease and foot-and-mouth disease.

The low adoption rates of livestock vaccines in Tanzania (and Africa more broadly) can be attributed to several supply, demand, and informational factors. First, the available vaccines in Tanzania may not completely protect against disease (Railey et al. 2018). Second, due to limited disease surveillance and awareness of the etiology of many adverse animal health outcomes in Tanzania, available vaccines (that are generally produced outside the country) may not protect against those diseases that cause the greatest actual losses. Third, the vaccine distribution system is marred by poor transport infrastructure (Waithanji, Mtimet, and Muindi 2019). In addition, vaccine cost, poor access, and a lack of information may limit the demand for vaccines (Homewood et al. 2006; Railey and Marsh 2019; Railey et al. 2019). 
Our analytical model focuses on general disease losses $L^{*}=L\left(v^{*}, n^{*}, l^{*} ; g, \rho, k, \gamma\right)$. Our data distinguish between livestock abortions and other livestock deaths for three species -cattle, sheep, and goats. Average Cattle, Sheep, and Goat Disease Deaths in the past 12 months in the sample are 1.5, 4.2, and 5.4, respectively. Mean deaths due to drought are $2.8,2.4$, and 2.6 for cattle, sheep, and goats in the preceding year, respectively. The disease and drought-related death measures are based on respondent recall. The average numbers of Cattle, Sheep, and Goat Livestock Abortions reported in the past 12 months by the household are $0.59,1.12$, and 2.10 , respectively (Table 2).

Cattle, Sheep, and Goat Introductions (represented by $n$ ) are count variables for the number of livestock of each type introduced into the herd from any source in the past 12 months. Sources of animal introductions include purchases from the livestock market, borrowing, and gifts from informal networks of kin in our sample. Cattle, Sheep, and Goat Introductions means are 1.61, 0.78, and 1.5, respectively (Table 2).

The mean gross herd size (net of introductions, $y$, in our model) is 54, 61, and 64 for cattle, sheep, and goats, respectively, and is represented by the variables Cattle, Sheep, and Goats.

We utilize a set of variables relating to grazing and watering practices, which we hypothesize may affect disease transmission through interherd contact. On average, in our sample, households cover about $10 \mathrm{~km}$ of Transhumance Distance seasonally to find suitable grazing areas, and they travel, on average, for about an hour daily for grazing and watering purposes (Grazing Time and Watering Time, respectively). To capture the village-level disease environment within which each household resides, we create Sub-Village Vaccination, Sub-Village Disease Deaths, and Sub-Village Abortion rates. Table 1 provides information on how these subvillage averages for vaccinations, disease deaths, and abortions are created. These variables help as exogenous instruments in the identification of our endogenous variables.

\section{Estimation}

To test our hypotheses and estimate the relationships between management practices and disease outcomes, we estimate (i) the effect of disease prevention (vaccinations) on disease-related deaths and (ii) the effect of herd accumulation on abortions and disease-related deaths. Vaccinations and herd introductions are endogenous variables. A standard two-stage instrumental variable approach is, therefore, used (Greene 2011). In stage 1, reduced form equations for vaccinations ( $v$ ) and Cattle, Sheep, and Goat Introductions $(n)$ are estimated first based on control variables and including additional exogenous variables in the equation. In stage 2 , the predicted values from these first-stage regressions are included in the outcome regressions as instruments in place of the original endogenous variables. This process, in principle, purges correlation between endogenous regressors and the regression disturbance that is the source of bias.

\section{Vaccinations and disease deaths}

Our aim is to estimate the relationship between Vaccinations ( $v)$ and Cattle, Sheep, and Goat Disease Deaths $(\boldsymbol{d})$. Households may choose to vaccinate their animals when the disease burden is high, and therefore, there may be bidirectional causality between vaccinations and disease-related losses. Furthermore, vaccinations are a management decision and may depend on several unobserved factors. Therefore, we use instrumental variables to obtain consistent estimates that minimize the bias introduced by the 
potential endogeneity of these decisions. Therefore, the first-stage regression equation that describes vaccine demand is as follows:

$$
v=f_{v}\left(\boldsymbol{X}_{1}, Z_{1}, Z_{2}\right)+\varepsilon_{v}
$$

where $f_{v}(\cdot)$ can be interpreted as a predicted value conditional on its regressors and $\varepsilon_{v}$ as a random error. $\boldsymbol{X}_{1}$ contains household-level variables like preexisting herd size and grazing practices of the household. The Sub-Village Vaccination average $\left(Z_{1}\right)$ is the exogenous variable calculated as the subvillage vaccination rate averaged over all households in the sample except the household represented in a given record. This "leave-out" vaccination rate is hypothesized to correlate with household's vaccination decisions but is assumed to affect only dependent variables through its effect on vaccinations $(v) . Z_{1}$ accounts for sub-village-level exogenous factors affecting the local supply of vaccinations and factors affecting general vaccination demand in the subvillage (e.g., general information and acceptance of vaccinations in the area). ${ }^{3} Z_{2}$ is the subvillage disease death that captures regional disease burden. ${ }^{4}$

The second-stage regression equation for livestock deaths is as follows:

$$
d_{i}=f_{d_{i}}\left(v^{*}, X_{1}, Z_{2}\right)+\varepsilon_{d_{i}}
$$

where $d_{i}$ represents disease-related deaths for each livestock species $i \in$ (Cattle, Sheep, Goats): one regression for each species. $\boldsymbol{X}_{1}$ is the control variables, as described above, and $Z_{2}$ is the subvillage disease death average that controls for regional disease burdens. ${ }^{5}$

Functional forms $f_{\mathrm{v}}($.$) and f_{\mathrm{d}_{i}}($.$) are chosen from the Poisson/Negative binomial$ family, since $v$ and $d_{i}$ are all count variables. Because predicted values from firststage regressions are included in the second-stage regressions, the covariance matrix for each second-stage equation is adjusted to obtain unbiased standard errors. ${ }^{6}$

\footnotetext{
${ }^{3}$ In addition to vaccinations, quarantine practices like separating the newly introduced animal from herd to identify disease symptoms or treatment with acaricide or anthelmintics prior to introduction can also be important disease prevention strategies, but our data do not allow us to capture these practices with any accuracy. Vaccination rates also depend on vaccination supply factors such as ease of access and cost. However, our data are limited in this regard.

${ }^{4}$ The intent of these subvillage means is to capture by proxy the regional disease burden based on household outcomes beyond the control of the household represented by a given record. It is not an attempt to infer how the behavior of other households in the village affects the behavior of the household in question, and as such, does not directly implicate the reflection effect identified by Manski (1993).

${ }^{5}$ Since the data were collected at a central point and households could choose into being interviewed or not, we also insert an inverse Mills ratio in each of the second-stage equations to test whether selection model results differed from other model results (Heckman 1979). The inverse Mills ratio was estimated based on a sample that includes nonparticipants but contains a smaller variable set. We estimate a probit model of choosing to attend the central point versus not with distance to the central point, socioeconomic status of the household, and herd size as regressors. The coefficient on the inverse Mills ratio is never significant and the results of the two models do not differ significantly, so we provide results only for the model without the selection correction.

${ }^{6}$ The covariance adjustment is as follows. The maximum likelihood covariance matrix is $\hat{\boldsymbol{\sigma}}^{2}\left(\boldsymbol{Z}^{\prime} \boldsymbol{X}\left(\boldsymbol{X}^{\prime} \boldsymbol{X}\right)^{-1} \boldsymbol{X}^{\prime} \boldsymbol{Z}\right)^{-1}$, where the $Z$ s are potentially endogenous variables and the $X s$ are exogenous (Greene 2011). This estimate is biased because the standard second-stage estimated variance $\hat{\sigma}^{2}=n^{-1}(\boldsymbol{y}-\hat{\mathbf{Z}} \boldsymbol{\beta})^{\prime}(\boldsymbol{y}-\hat{\mathbf{Z}} \boldsymbol{\beta})$ is calculated using the predicted values from the first-stage regressions. A consistent estimate of the $\sigma^{2}$ is calculated as $\hat{\sigma}_{\mathrm{ub}}^{2}=n^{-1}(\boldsymbol{y}-\boldsymbol{Z} \boldsymbol{\beta})(\boldsymbol{y}-\boldsymbol{Z} \boldsymbol{\beta})^{\prime}$, based on the original values of instrumented variables in $\boldsymbol{Z}$, and the unbiased covariance matrix is calculated using, $\hat{\sigma}_{\mathrm{ub}}^{2}$, the unbiased estimate of $\sigma^{2}$.
} 


\section{Herd introductions and disease losses}

In addition to estimating the effect of vaccinations on deaths, we estimate the relationship between Cattle, Sheep, and Goat Introductions (n), Cattle, Sheep, and Goat Disease Deaths $(\boldsymbol{d})$, and Cattle, Sheep, and Goat Abortions (a). Households may choose to introduce more animals in their herd to maintain herd size if they have lost animals due to a disease, but these introductions may also introduce pathogens that can cause disease. There may, therefore, be bidirectional causality between introductions and diseaserelated losses. To account for this, we use instrumental variables to minimize the bias introduced by the potential endogeneity of these decisions.

The first-stage regression equation that describes herd introduction demand is as follows:

$$
n_{i}=f_{n_{i}}\left(X_{1}, Z_{2}, Z_{3}\right)+\varepsilon_{n_{i}}
$$

where $n_{i} \in \boldsymbol{n}$ represents the introductions for each livestock species $i \in$ (Cattle, Sheep, Goats). $\boldsymbol{X}_{1}$ contains household-level variables including preexisting herd size and grazing practices of the household. $Z_{2}$ is the subvillage disease outcome that captures regional disease burden. $Z_{3}$ captures the livestock deaths that occurred due to a drought. These drought-related deaths are used as exogenous instruments that are assumed to affect disease-related losses only through herd introductions. A concern regarding our instrument here is that the incidence of drought may affect animals' ability to fight off disease, as animals become malnourished and are expected to be less healthy during a drought. This likely positive correlation between the instrument and the outcome variables means that we will potentially overestimate the impact of herd introductions on disease-related outcomes. In that sense, we will likely obtain the upper bound of the effect of introductions on disease-related outcomes. Functional form $f_{n_{i}}($.$) is chosen from the Poisson/Negative binomial family, since variables contained$ in each $n_{i} \in \boldsymbol{n}$ are count variables.

Predictions $\boldsymbol{n}^{\star}$ from regression equation 7 are used as regressors in a pair of secondstage regressions for death and abortion outcomes:

$$
\begin{aligned}
& d_{i}=f_{d_{i}}\left(\boldsymbol{n}^{*}, X_{1}, Z_{2}\right)+\varepsilon_{d_{i}} \\
& a_{i}=f_{a_{i}}\left(\boldsymbol{n}^{*}, X_{1}, Z_{2}\right)+\varepsilon_{a_{i}}
\end{aligned}
$$

where $d_{i}$ and $a_{i}$ are deaths and abortions for each livestock species $i \in$ (Cattle, Sheep, Goats), respectively. $X_{1}$ is the control variable, as described above, and $Z_{2}$ is the subvillage disease outcome average that controls for regional disease burden. The functional forms are again chosen from the Poisson/Negative binomial family, since $d_{i}$ and $a_{i}$ are count variables. ${ }^{7}$ Because predicted values from first-stage regressions are included in

\footnotetext{
${ }^{7}$ Since the data were collected at a central point and households could choose into being interviewed or not, we have also inserted the inverse Mills ratio in each of the second-stage equations to test whether selection model results differed from other model results (Heckman 1979). The inverse Mills ratio was estimated based on a sample that includes nonparticipants but contains a smaller variable set. A probit model of choosing to attend the central point versus not with distance to the central point, socioeconomic status of the household, and herd size as regressors. The coefficient on the inverse Mills ratio is never significant and the results of the two models do not differ significantly, so we provide results only for the model without the selection correction.
} 
the second-stage regressions, the covariance matrix for each second-stage equation is adjusted to obtain unbiased standard errors, as described in footnote 7.

\section{Results}

\section{Vaccinations and disease-related deaths}

The results for the first-stage Vaccination (equation 5) are provided in Table 3. The Sub-Village Vaccination averages are positively related to Vaccination rates. This may indicate the presence of peer effects, learning, or correlations in vaccination access within villages. Informal qualitative data from interaction with respondents during data collection indicate that some communities in the sample have better access to and relationships with veterinary services, and hence, vaccination adoption could be a community-wide phenomenon (Virhia 2019, Ch. 6). In some cases, livestock vaccination in the study area is centrally coordinated through the Ministry of Livestock and Fisheries Development, typically with mass vaccination of a large proportion of animals in the same village or subvillage at the same time. However, some vaccinations like that against ECF are dependent on a household's own initiative and are not actively distributed by government programs.

Table 4 provides the results of Disease Death (equation 6). As discussed in the estimation section, livestock Vaccinations are replaced with instrumental variables produced as predictions from the equations presented in Tables 3. For the Cattle Disease Death regression (Column 1, Table 4), Vaccinations are shown to decrease the number of disease-related deaths by 1.25, though this marginal effect is not statistically significant at conventional levels. However, for the Sheep and Goat Disease Death regression (Columns 2 and 3, Table 4), vaccination for each additional disease is shown to decrease the number of disease-related deaths in sheep and goats. The estimated marginal effect for each additional vaccine type is $-7.11(\mathrm{p}<0.001)$ and $-5.59(\mathrm{p}<0.001)$ for goats and sheep, respectively. ${ }^{8}$ So, vaccinating against one additional disease is related to a decrease of about seven disease-related deaths per year in goats and six deaths per year in sheep. To put this in context, only 18.5 percent of households have used any type of vaccine in the last 12 months, and the average herd sizes of goats and sheep in our sample are 61 and 64, respectively, so the addition of one vaccine type at sample means can save about 10 percent of the small goat and sheep herd size from disease-related deaths in a representative household in the sample. Ahmed et al. (2019) show that small stock faces a higher disease risk in northern Tanzania, and therefore, the marginal benefit of vaccinations may be higher in small stock. These results corroborate hypotheses 1 and 2 of the theoretical model.

The most frequently used vaccines in our sample are for CBPP and anthrax, followed by vaccines for lumpy skin disease and foot-and-mouth disease, respectively. ${ }^{9}$

\footnotetext{
${ }^{8}$ The highest reported number of livestock vaccines in the sample is 3, which is reported by only $1 \%$ of the data. Therefore, to test the robustness of our estimates, we provide estimates when Vaccinations are modeled as a dichotomous variable (as opposed to a count variable). Supplementary Table Al shows that our estimates are robust across the two specifications. Furthermore, Disease Death regressions without instrumenting for vaccinations are provided in Supplementary Table A2 of the Appendix for a comparison. Columns 1-3 of Supplementary Table A2 show the results when vaccination is a count variable, while Columns 4-6 provide results when vaccination is a dichotomous variable.

${ }^{9}$ Some of the vaccinations used in the sample are species-specific, e.g., East Coast fever vaccine may only directly affect cattle health and may have no direct effect on the health of sheep and goats.
} 
Table 3. First-stage vaccination equation results-Poisson regression

\begin{tabular}{lcc}
\hline $\begin{array}{l}\text { Dependent variable, } \\
\text { Vaccinations }\end{array}$ & Coefficients (SE) & Marginal effects \\
\hline Subvillage vaccination & $1.31^{\star \star \star}(0.370)$ & $0.274^{\star \star \star}(0.081)$ \\
\hline Transhumance distance & $0.019(0.088)$ & $0.003(0.018)$ \\
\hline Cattle & $0.216(0.132)$ & $0.045(0.028)$ \\
\hline Goats & $0.095(0.095)$ & $0.019(0.019)$ \\
\hline Sheep & $0.106(0.093)$ & $0.022(0.019)$ \\
\hline Watering time & $-0.069(0.120)$ & $-0.014(0.025)$ \\
\hline Grazing time & $-0.136(0.122)$ & $-0.028(0.025)$ \\
\hline Subvillage disease death & $-0.026(0.016)$ & $-0.001(0.001)$ \\
\hline $\begin{array}{l}\text { Vuong (1989) test statistic } \\
\text { Likelihood Ratio (LR) test: Negative Binomial (NB) vs. Poisson } \\
(p-v a l u e)\end{array}$ & 0.0023 \\
\hline
\end{tabular}

${ }^{* \star \star},{ }^{* \star},{ }^{*}$ indicate significance at 1 percent, 5 percent, and 10 percent levels, respectively.

Table 4. The effect of vaccinations on livestock disease death-marginal effects from zero-inflated Poisson regression

\begin{tabular}{lccr}
\hline & $\begin{array}{c}\text { Cattle disease } \\
\text { death }\end{array}$ & $\begin{array}{c}\text { Goat disease } \\
\text { death }\end{array}$ & \multicolumn{1}{c}{$\begin{array}{c}\text { Sheep disease } \\
\text { death }\end{array}$} \\
\hline Vaccinations $^{\mathrm{a}}$ & $-1.241(1.211)$ & $-7.11^{\star \star \star}(2.12)$ & $-5.59^{\star \star \star}(1.98)$ \\
\hline Cattle & $1.014^{\star \star \star}(0.129)$ & $0.046(0.093)$ & $0.502^{\star \star \star}(0.117)$ \\
\hline Sheep & $-0.046(0.132)$ & $0.240^{\star \star \star}(0.070)$ & $0.709^{\star \star \star}(0.105)$ \\
\hline Goats & $-0.276^{\star \star}(0.132)$ & $0.866^{\star \star \star}(0.091)$ & $0.067(0.097)$ \\
\hline Transhumance distance & $0.105(0.069)$ & $0.035(0.054)$ & $-0.173^{\star \star \star}(0.067)$ \\
\hline Grazing time & $0.013(0.089)$ & $0.137^{\star}(0.074)$ & $0.017(0.095)$ \\
\hline Watering time & $-0.003(0.100)$ & $-0.104(0.075)$ & $-0.319^{\star \star \star}(0.094)$ \\
\hline Subvillage disease death & $-0.033(0.034)$ & $0.082^{\star \star \star}(0.031)$ & $0.109^{\star \star \star}(0.034)$ \\
\hline Vuong test $(p-v a l u e)$ & $4.54(0.000)$ & $5.31(0.000)$ & $5.42(0.000)$ \\
\hline
\end{tabular}

Note: Standard errors for marginal effects are estimated via the delta method.

${ }^{\text {a }}$ Predicted values from the first-stage regression of Vaccinations.

${ }^{\star \star \star},{ }^{\star \star},{ }^{*}$ indicate significance at 1 percent, 5 percent, and 10 percent levels, respectively.

Anthrax is an important cause of mortality in all ruminants (Lembo et al. 2011), while CBPP is an important disease for only cattle (Kairu-Wanyoike et al. 2014). The active vaccination of these sources of disease deaths seems likely to be the basis of the marginal effect of vaccinations on disease deaths described above. Indeed, Supplementary Table A3 (Columns 1-3) shows that anthrax vaccine adoption is associated with large decreases in mortality in sheep and goats and could 
be an important mechanism behind the reduction in mortality in small stock. Moreover, CBPP vaccine seems to be contributing to reducing cattle disease deaths, though the effect size is modest. ${ }^{10}$

The exclusion variable used to identify Vaccinations is leave-out Sub-village Vaccinations. These subvillage vaccination averages may not be completely random, and higher subvillage means may reflect a common cause. The Ministry of Livestock and Fisheries Development conducts some vaccination drives in villages and subvillages. If the Ministry employs a vaccination drive in response to a disease threat, the magnitude of coefficient on Vaccinations may be biased upward. In that sense, we are perhaps estimating an upper bound of the effect of vaccines on livestock mortality.

These results have important policy implications in terms of minimizing the disease risk in livestock and improving livestock productivity in low-income settings. Vaccination availability and use can help protect the herd from illnesses that, in turn, affect the income and nutrition of households in rural settings. It is also notable that livestock keepers in this setting are currently using only a limited number of vaccines against a limited number of diseases. Moreover, we have no information on vaccination practices used, such as what proportion of the herd is vaccinated. It could be expected that a wider uptake of vaccination, whole herd vaccination, and vaccination against the major causes of mortality in the region would contribute to reductions in disease losses and may have indirect effects on household welfare more broadly. Indeed, other studies have shown human capital and productivity benefits of livestock vaccinations and antimicrobials in terms of higher nutritional intake, control of zoonotic diseases and food-borne illnesses, and higher rates of schooling (Mosites et al. 2015; Marsh et al. 2016). The economic and behavioral factors associated with livestock vaccine adoption warrant additional research to better understand and enhance vaccine adoption and ensure better animal health, especially in low- and middle-income countries.

\section{Herd introductions and disease-related losses}

Table 5 provides the first-stage negative binomial regression coefficients for Cattle, Sheep, and Goat Introductions. Cattle introductions are positively related to drought-related cattle deaths, though the magnitude is small. Similarly, goat introductions are positively associated with cattle and goat drought deaths, while cattle appear to be replaced most often with goats. This relationship between drought-related death and introduction is not one-to-one. Since replacement is costly and one death is not replaced by one introduction, transfers into the herd may not compensate fully for the negative shocks, suggesting the limited effectiveness of restocking as a risk

\footnotetext{
${ }^{10}$ Supplementary Table A4 provides the results of the relationship between vaccinations and livestock abortions. We find a positive relationship between vaccinations and abortions in the case of cattle and goats, and no relationship in the case of sheep. A positive association between vaccinations and abortions could be a result of two things. First, vaccines may be used when disease risk is high to reduce negative disease outcomes, and a weak instrument for vaccination may result in a positive association between a predictor and an outcome. However, our instrument is relatively strong, given the first-stage results in Table 3. Second, vaccinated diseases (such as CBPP, foot-and-mouth disease, and lumpy skin disease) are not major causes of abortion in our sample. This latter set of extra-sample facts warrants additional skepticism about the estimated vaccination/abortion relationships, so an analysis of vaccinations in connection with livestock abortions is presented in the Supplementary Appendix.
} 
Table 5. First-stage cattle, sheep, and goat introduction (negative binomial) regressions

\begin{tabular}{lccc}
\hline & $\begin{array}{c}\text { Cattle } \\
\text { introductions }\end{array}$ & $\begin{array}{c}\text { Sheep } \\
\text { introductions }\end{array}$ & $\begin{array}{c}\text { Goat } \\
\text { introductions }\end{array}$ \\
\hline Cattle drought death & $0.027^{\star \star \star}(0.007)$ & $0.013(0.009)$ & $0.132^{\star \star \star}(0.046)$ \\
\hline Sheep drought death & $-0.004(0.003)$ & $-0.012(0.011)$ & $0.001(0.002)$ \\
\hline Goats drought death & $0.001(0.0009)$ & $0.007(0.009)$ & $0.093^{\star \star}(0.040)$ \\
\hline Cattle & $-0.006^{\star \star}(0.003)$ & $-0.001(0.0009)$ & $-0.018^{\star \star \star}(0.002)$ \\
\hline Sheep & $0.267^{\star \star \star}(0.048)$ & $-0.492^{\star \star}(0.191)$ & $0.388^{\star \star \star}(0.090)$ \\
\hline Goats & $0.431^{\star \star \star}(0.061)$ & $0.861^{\star \star \star}(0.225)$ & $1.68^{\star \star *}(0.181)$ \\
\hline Transhumance distance & $-0.015^{\star \star *}(0.003)$ & $-0.094^{\star \star}(0.037)$ & $0.005(0.005)$ \\
\hline Watering time & $0.131^{\star \star}(0.051)$ & $0.874^{\star \star \star}(0.301)$ & $-0.027^{\star \star *}(0.008)$ \\
\hline Subvillage disease Death & $0.882^{\star \star \star}(0.142)$ & $-0.296^{\star}(0.175)$ & $0.022^{\star \star \star}(0.002)$ \\
\hline
\end{tabular}

${ }^{\star \star \star},{ }^{\star \star},{ }^{*}$ indicate significance at 1 percent, 5 percent, and 10 percent levels, respectively.

management strategy. Given that the magnitude of introductions and negative asset shocks differs significantly, subsistence farmers with small herd sizes may be at risk of losing all of their herd. In expectation of large mortality losses, some farmers may have larger ex ante herd size, so that they can have a reasonable ex post herd size (Lybbert et al. 2004; Kazianga and Udry 2006; McPeak 2006), which may explain the positive herd sizes in Table 2. It is difficult, however, to infer whether restocking is pursued as precautionary saving or as ex post herd rehabilitation.

Table 6 provides the results for livestock disease-related deaths and livestock abortion regressions (equation 8). Our results do not corroborate hypothesis 3: we do not find robust evidence of herd restocking being a risk factor in increasing disease-related deaths and abortions. There may be several reasons for these other than data limitations. First, other mechanisms of interherd contact like communal watering, grazing, and breeding may be predominantly responsible for disease spread. Other studies have shown the importance of these other mechanisms in disease transfer and spread (Ahmed et al. 2018; Ogola et al. 2018). However, our data do not allow us to tease out the comparative role of each of the above-mentioned mechanisms in disease transfer. Second, abortions and deaths may be extreme symptoms or outcomes of diseases, and our analysis may miss other (unobserved) less extreme symptoms associated with disease-causing pathogens. The literature has shown that herd restocking and movement is a risk factor for a number of diseases (Fèvre et al. 2001; Gardner, Willeberg, and Mousing 2002; Marshall, Carpenter, and Thunes 2009; Chaters et al. 2019). Third, households may be able to minimize the disease transmission through quarantine and other disease preventative practices. ${ }^{11}$ Our data do not allow us to examine these attributes to disease prevention associated with herd introductions.

\footnotetext{
${ }^{11}$ Livestock keepers did not report movement control and region-level quarantine measures in the sample. Although such measures may be necessary to limit the spread of an outbreak, there may be costs associated with such policy instruments. For example, Limon et al. (2020) show a negative relationship between regional disease-control and quarantine measures and economic and food security of households through reductions in livestock sales.
} 
Table 6. The effect of introductions on livestock deaths and abortions-marginal effects from negative binomial regressions

\begin{tabular}{|c|c|c|c|c|c|c|}
\hline & $\begin{array}{l}\text { Cattle disease } \\
\text { death }\end{array}$ & $\begin{array}{c}\text { Cattle } \\
\text { abortions }\end{array}$ & $\begin{array}{l}\text { Goats disease } \\
\text { death }\end{array}$ & $\begin{array}{c}\text { Goats } \\
\text { abortions }\end{array}$ & $\begin{array}{l}\text { Sheep disease } \\
\text { death }\end{array}$ & $\begin{array}{l}\text { Sheep } \\
\text { abortions }\end{array}$ \\
\hline Cattle introductions ${ }^{a}$ & $0.002(0.008)$ & $0.008(0.019)$ & - & - & - & - \\
\hline Sheep introductions ${ }^{a}$ & - & - & - & - & $-0.267(0.434)$ & $0.002(0.002)$ \\
\hline Cattle & $0.005^{\star \star}(0.002)$ & $-0.006(0.01)$ & $0.005(0.005)$ & $0.003(0.006)$ & $-0.011^{\star \star}(0.005)$ & $0.004(0.005)$ \\
\hline Transhumance distance & $0.006(0.012)$ & $-0.003^{*}(0.002)$ & $0.002(0.002)$ & $-0.034^{\star \star}(0.013)$ & $-0.076(0.107)$ & $-0.003(0.005)$ \\
\hline Watering time & $-0.001(0.002)$ & $0.007^{\star}(0.003)$ & $0.015(0.038)$ & $0.641^{\star \star \star}(0.171)$ & $0.814(0.961)$ & $0.111(0.130)$ \\
\hline Subvillage disease deaths & $0.002^{*}(0.001)$ & - & $-0.017(0.013)$ & - & $-0.22(0.308)$ & - \\
\hline Subvillage abortions & - & $0.09^{\star \star \star}(0.01)$ & - & $0.021(0.023)$ & - & $0.074^{\star \star \star}(0.019)$ \\
\hline
\end{tabular}

Note: Standard errors for marginal effects are estimated via the delta method.

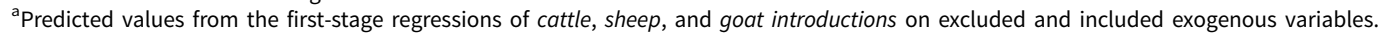

$* * *,{ }^{* \star},{ }^{*}$ indicate significance at 1 percent, 5 percent, and 10 percent levels, respectively. 
Bidirectional causality between Disease Death, Abortions, and Introductions is particularly difficult to statistically differentiate given our data limitations. Herd owners may replace livestock to replenish their herd after a death, but livestock Introductions may also introduce disease into the herd and affect the incidence of disease-related death and abortions. The identification strategy and the strength of the instruments used in our analysis become critical. F-statistics in the first-stage regressions can be used to assess instrument strength (Staiger and Stock 1997; Greene 2011). The first-stage F-statistics of the joint test of instruments (Cattle, Sheep, and Goat Drought Deaths) are 26.71, 9.5, and 27.90 for Cattle, Sheep, and Goat Introduction equations, respectively. If F-statistics are generally greater than 10, then instrumental variable bias is usually less than 10 percent, suggesting that we do not have significant instrumental variable bias.

Our instrument for Introductions was Drought Deaths in the first stage (Table 5). However, drought-related deaths can be potentially positively correlated with disease-related deaths, as droughts or diseases can intensify each other's impacts on animal health and well-being. Such a positive correlation between the instrument and the dependent variable can bias our estimates upward. However, our estimates of the effect of introduction on disease-related death are zero (as they are when we do not use instrumental variables [Supplementary Tables A5 and A6]), suggesting that a potentially positive correlation between the instrument and the dependent variable is not a concern for our estimates.

Herd sizes are positively related to disease losses in Table 6. This could follow from the fact that there are more animals available to become ill; but it could also be driven in part by a lower labor per animal ratio and less care per animal, by differences in management that influence pathogen transmission, or because disease control may be costly for larger herds. Herd size has been identified as a risk factor for infection prevalence for several livestock diseases (Gardner, Willeberg, and Mousing 2002; Makita et al. 2011; Rizzo et al. 2016). Transhumance and daily grazing activities are statistically significant at conventional levels in this regression, corroborating studies that show that these activities lead to higher disease transmission (Bronsvoort et al. 2004; Rufael et al. 2008; Schoonman and Swai 2010; Ahmed et al. 2018).

The cross-sectional and observational nature of our data presents two challenges. First, the endogeneity between management practices and outcomes is difficult to disentangle. Future research using panel and/or longitudinal data may help in disentangling herd introductions made as ex ante precautionary savings and ex post herd replacement. Second, we are unable to provide evidence on the changes in herd composition over time, which can be important for livestock income and household wellbeing in these particular communities. Furthermore, the demand for introductions may be sensitive to sex, breed, age, and species of the animal. While we examine demand for introductions disaggregated by species, we are unable to examine transfers disaggregated by sex or breed of the animal, which may be important in this context.

\section{Conclusion}

Vaccinations and herd restocking are two important herd management strategies, especially in relation to livestock disease outcomes. While herd composition and dynamics in relation to poverty and insurance are widely discussed in the literature, evidence on demand for restocking and vaccination and their relationship with livestock disease losses and household welfare is limited. We contribute to the understanding of restocking and vaccinations and their relationships with disease losses by developing a 
theoretical model of these livestock management decisions in the context of herd disease challenge and use this model to derive a set of hypotheses. Livestock management decisions and outcomes may be jointly (endogenously) determined, and therefore, instrumental variables are used to test hypotheses about livestock introduction, vaccination, and their relationship with abortions and disease-related deaths.

We do not find robust evidence of herd introductions as a risk factor for increased livestock deaths and abortions. However, we find evidence of the effectiveness of vaccinations in reducing disease deaths. These results have important policy implications in terms of the relationship between livestock disease preventative technologies and herd welfare, which is central to improving household welfare through its impact on income generation, savings, and nutrition. Given the large marginal benefit of additional vaccines and low uptake of livestock vaccines in our sample, our results also highlight important policy implications in terms of vaccine supply chains and farmer's incentives to vaccinate given disease risk. Improving vaccination coverage and uptake can be used as a tool to alleviate poverty in livestock-keeping communities by protecting household assets associated with savings and nutrition.

Supplementary material. The supplementary material for this article can be found at https://doi.org/10. 1017/age.2021.11

Acknowledgments. We would like to thank the editor, two anonymous reviewers, Philip Wandschneider, Benjamin Cowan, and Thomas Marsh for helpful comments.

Funding Statement. This work was supported by funding from the Biotechnology and Biological Sciences Research Council, the Department for International Development, the Economic \& Social Research Council, the Medical Research Council, the Natural Environment Research Council, and the Defence Science \& Technology Laboratory under the Zoonoses and Emerging Livestock Systems program (Grant No. BB/L018926/1).

Ethical Standard. All participants conducting questionnaires were provided written informed consent. The protocols, questionnaire, and consent procedures were approved by the ethical review committees of the Kilimanjaro Christian Medical Centre $(\mathrm{KCMC} / 832)$ and the National Institute of Medical Research (NIMR/2028) in Tanzania, and in the UK by the ethical review committee of the College of Medical, Veterinary and Life Sciences, University of Glasgow.

Conflicts of Interest. The authors declare no conflicts of interest.

\section{References}

Ahmed, H., D.R. Call, R.J. Quinlan, and J.K. Yoder. 2018. "Relationships Between Livestock Grazing Practices, Disease Risk, and Antimicrobial Use among East African Agropastoralists." Environment and Development Economics 23(1): 80-97.

Ahmed, H., J. Yoder, W.A. de Glanville, A. Davis, T.J. Kibona, B.T. Mmbaga, F. Lankester, E.S. Swai, and S. Cleaveland. 2019. "Economic Burden of Livestock Disease and Drought in Northern Tanzania." Journal of Development and Agricultural Economics 11(6): 140-151.

Anderson, R.M., and R.M. May. 1992. Infectious Diseases of Humans: Dynamics and Control. New York, USA: Oxford University Press.

Barrett, C.B. 2005. "Rural Poverty Dynamics: Development Policy Implications." Agricultural Economics 32: $45-60$.

Bronsvoort, B.d.C., C. Nfon, S.M. Hamman, V.N. Tanya, R.P. Kitching, and K.L. Morgan. 2004. "Risk Factors for Herdsman-Reported Foot-and-Mouth Disease in the Adamawa Province of Cameroon." Preventive Veterinary Medicine 66(1-4): 127-139.

Carter, M.R. 1988. "Equilibrium Credit Rationing of Small Farm Agriculture." Journal of Development Economics 28(1): 83-103. 
Carter, M.R., and C.B. Barrett. 2006. "The Economics of Poverty Traps and Persistent Poverty: An Asset-Based Approach." The Journal of Development Studies 42(2): 178-199.

Chaters, G.L., P.C.D. Johnson, S. Cleaveland, J. Crispell, W.A. De Glanville, T. Doherty, L. Matthews, S. Mohr, O.M. Nyasebwa, G. Rossi, L.C.M. Salvador, E. Swai, and R.R. Kao. 2019. "Analysing Livestock Network Data for Infectious Disease Control: An Argument for Routine Data Collection in Emerging Economies.” Philosophical Transactions of the Royal Society B 374(1776): 20180264.

de Glanville, W.A., A. Davis, K.J. Allan, J. Buza, J.R. Claxton, J.A. Crump, et al. 2020. "Classification and Characterisation of Livestock Production Systems in Northern Tanzania." PLoS One 15(12): e0229478. doi:10.1371/journal.pone.0229478.

Fafchamps, M., C. Udry, and K. Czukas. 1998. "Drought and Saving in West Africa: Are Livestock a Buffer Stock?” Journal of Development Economics 55(2): 273-305.

Fèvre, E.M., P.G. Coleman, M. Odiit, J.W. Magona, S.C. Welburn, and M.E. Woolhouse. 2001. "The Origins of a New Trypanosoma Brucei Rhodesiense Sleeping Sickness Outbreak in Eastern Uganda." The Lancet 358(9282): 625-628.

Gardner, I.A., P. Willeberg, and J. Mousing. 2002. "Empirical and Theoretical Evidence for Herd Size as a Risk Factor for Swine Diseases.” Animal Health Research Reviews 3(1): 43-55.

Greene, W. 2011. Econometric Analysis, 7th Edition. Upper Saddle River, NJ: Prentice Hall.

Heckman, J.J. 1979. “Sample Selection Bias as a Specification Error.” Econometrica 47(1): 153-161.

Homewood, K., P. Trench, S. Randall, G. Lynen, and B. Bishop. 2006. "Livestock Health and Socio-economic Impacts of a Veterinary Intervention in Maasailand: Infection-and-Treatment Vaccine Against East Coast Fever." Agricultural Systems 89(2-3): 248-271.

Kairu-Wanyoike, S.W., H. Kiara, C. Heffernan, S. Kaitibie, G.K. Gitau, D. McKeever, and N.M. Taylor. 2014. "Control of Contagious Bovine Pleuropneumonia: Knowledge, Attitudes, Perceptions and Practices in Narok District of Kenya." Preventive Veterinary Medicine 115(3-4): 143-156.

Kazianga, H., and C. Udry. 2006. "Consumption Smoothing? Livestock, Insurance and Drought in Rural Burkina Faso." Journal of Development Economics 79(2): 413-446.

Knight-Jones, T.J.D., M. McLaws, and J. Rushton. 2017. "Foot-and-Mouth Disease Impact on Smallholders-What Do We Know, What Don't We Know and How Can We Find Out More?" Transboundary and Emerging Diseases 64(4): 1079-1094.

Lembo, T., K. Hampson, H. Auty, C.A. Beesley, P. Bessell, C. Packer, J. Halliday, et al. 2011. "Serologic Surveillance of Anthrax in the Serengeti Ecosystem, Tanzania, 1996-2009.” Emerging Infectious Diseases 17(3): 387.

Limon, G., G. Ulziibat, B. Sandag, S. Dorj, D. Purevtseren, B. Khishgee, G. Basan, et al. 2020. "Socio-economic Impact of Foot-and-Mouth Disease Outbreaks and Control Measures: An Analysis of Mongolian Outbreaks in 2017." Transboundary and Emerging Diseases 67(5): 2034-2049.

Lybbert, T.J., C.B. Barrett, S. Desta, and D. Layne Coppock. 2004. "Stochastic Wealth Dynamics and Risk Management among a Poor Population.” The Economic Journal 114(498): 750-777.

Makita, K., E.M. Fèvre, C. Waiswa, M.C. Eisler, M. Thrusfield, and S.C. Welburn. 2011. "Herd Prevalence of Bovine Brucellosis and Analysis of Risk Factors in Cattle in Urban and Peri-Urban Areas of the Kampala Economic Zone, Uganda.” BMC Veterinary Research 7(1): 1-8.

Manski, C.F. 1993. "Identification of Endogenous Social Effects: The Reflection Problem." The Review of Economic Studies 60(3): 531-542.

Marsh, T.L., J. Yoder, T. Deboch, T.F. McElwain, and G.H. Palmer. 2016. "Livestock Vaccinations Translate into Increased Human Capital and School Attendance by Girls." Science Advances 2(12): e1601410.

Marshall, E.S., T.E. Carpenter, and C. Thunes. 2009. "Results of a Survey to Estimate Cattle Movements and Contact Rates among Beef Herds in California, with Reference to the Potential Spread and Control of Foot-and-Mouth Disease." Journal of the American Veterinary Medical Association 235(5): 573-579.

McPeak, J. 2006. "Confronting the Risk of Asset Loss: What Role Do Livestock Transfers in Northern Kenya Play?” Journal of Development Economics 81(2): 415-437.

McPeak, J.G., and C.B. Barrett. 2001. "Differential Risk Exposure and Stochastic Poverty Traps among East African Pastoralists." American Journal of Agricultural Economics 83(3): 674-679.

Mosites, E.M., P.M. Rabinowitz, S.M. Thumbi, J.M. Montgomery, G.H. Palmer, S. May, A. Rowhani-Rahbar, M.L. Neuhouser, and J.L. Walson. 2015. "The Relationship Between Livestock 
Ownership and Child Stunting in Three Countries in Eastern Africa Using National Survey Data." PLoS One 10(9): e0136686.

Ogola, J., E.M. Fèvre, G.K. Gitau, R. Christley, G. Muchemi, and W.A. de Glanville. 2018. "The Topology of Between-Herd Cattle Contacts in a Mixed Farming Production System in Western Kenya." Preventive Veterinary Medicine 158: 43-50.

Railey, A.F., F. Lankester, T. Lembo, R. Reeve, G. Shirima, and T.L. Marsh. 2019. "Enhancing Livestock Vaccination Decision-Making Through Rapid Diagnostic Testing." World Development Perspectives 16: 100144.

Railey, A.F., T. Lembo, G.H. Palmer, G.M. Shirima, and T.L. Marsh. 2018. "Spatial and Temporal Risk as Drivers for Adoption of Foot and Mouth Disease Vaccination." Vaccine 36(33): 5077-5083.

Railey, A.F., and T.L. Marsh. 2019. "A Rational Explanation of Limited FMD Vaccine Uptake in Endemic Regions." Pathogens 8(4): 181.

Rizzo, F., N. Vitale, M. Ballardini, V. Borromeo, C. Luzzago, L. Chiavacci, and M.L. Mandola. 2016. "Q Fever Seroprevalence and Risk Factors in Sheep and Goats in Northwest Italy." Preventive Veterinary Medicine 130: 10-17.

Rufael, T., A. Catley, A. Bogale, M. Sahle, and Y. Shiferaw. 2008. "Foot and Mouth Disease in the Borana Pastoral System, Southern Ethiopia and Implications for Livelihoods and International Trade." Tropical Animal Health and Production 40(1): 29-38.

Santos, P., and C.B. Barrett. 2017 "Heterogeneous Wealth Dynamics: On the Roles of Risk and Ability." In The Economics of Poverty Traps Edited by Christopher B. Barrett, Michael R. Carter and Jean-Paul Chavas (pp. 265-290). Chicago, USA: University of Chicago Press.

Schoonman, L., and E.S. Swai. 2010. "Herd- and Animal-Level Risk Factors for Bovine Leptospirosis in Tanga Region of Tanzania." Tropical Animal Health and Production 42(7): 1565-1572.

Selby, R., K. Bardosh, K. Picozzi, C. Waiswa, and S.C. Welburn. 2013. "Cattle Movements and Trypanosomes: Restocking Efforts and the Spread of Trypanosoma Brucei Rhodesiense Sleeping Sickness in Post-conflict Uganda." Parasites \& Vectors 6(1): 1-12.

Staiger, D., and J.H. Stock. 1997. "Instrumental Variables Regression with Weak Instruments." Econometrica 65(3): 557-586.

Stevens, D.L. Jr, and A.R. Olsen. 2004. "Spatially Balanced Sampling of Natural Resources." Journal of the American Statistical Association 99(465): 262-278.

Taylor, J.E., and I. Adelman. 2003. "Agricultural Household Models: Genesis, Evolution, and Extensions." Review of Economics of the Household 1(1): 33-58.

Toth, R. 2015. "Traps and Thresholds in Pastoralist Mobility." American Journal of Agricultural Economics 97(1): 315-332.

Virhia, J. 2019. "Healthy Animals, Healthy People: Lived Experiences of Zoonotic Febrile Illness in Northern Tanzania." Ph.D. dissertation, University of Glasgow. Available at: http://theses.gla.ac.uk/79058/1/ Virhia2020phd.pdf.

Vuong, Q.H. 1989. "Likelihood Ratio Tests for Model Selection and Non-nested Hypotheses." Econometrica 57(2): 307-333.

Waithanji, E., S.W. Kairu-Wanyoike, and M. Liani. 2019. "The Role of Gender and Other Socioeconomic Factors in the Adoption of the Contagious Bovine Pleuropneumonia Vaccine: A Literature Review." East African Agricultural and Forestry Journal 83(3): 221-238.

Waithanji, E., N. Mtimet, and P. Muindi. 2019. "Contagious Bovine Pleuropneumonia Vaccine Delivery and Adoption by Women and Men in North-Eastern Kenya." The European Journal of Development Research 31(3): 364-387.

Cite this article: Ahmed H, Yoder J, de Glanville W, Davis A, Kibona TJ, Cleaveland S (2022). Relationships between vaccinations, herd introductions, and livestock losses in Northern Tanzania. Agricultural and Resource Economics Review 51, 1-19. https://doi.org/10.1017/age.2021.11 